\title{
Patient-centred consultations in a dispensary setting: a learning journey
}

\author{
Nina L Barnett, Kalveer Flora
}

- Additional material is published online only. To view please visit the journal online (http://dx.doi.org/10.1136/ ejhpharm-2016-000929)

Pharmacy Department, London North West Healthcare NHS Trust, London, UK

\section{Correspondence to} Professor Nina L Barnett, Pharmacy Department, London North West Healthcare NHS Trust, Northwick Park Hospital Watford Road, Harrow, Middlesex HA1 3UJ, UK nina.barnett@nhs.net

Received 26 February 2016 Revised 10 March 2016

Accepted 11 March 2016 Published Online First 5 April 2016
CrossMark

To cite: Barnett $\mathrm{NL}$, Flora K. Eur J Hosp Pharm 2017:24:107-109.

\begin{abstract}
Background Hospital dispensary consultations usually focus on telling your patients how to take medicines.

However, patient views are not always considered. We suggest that the value of a consultation lies in helping patients get the best health outcome from their medicines and this requires more than education. Pharmacy teams need to think differently about the way in which consultations are undertaken in order to improve effectiveness of medicines.
\end{abstract}

Objectives To explore development of patient-centred consultations in a hospital dispensary environment using a health coaching approach.

Method In April 2014, London North West Hospitals NHS Trust Pharmacy Department commissioned a 2-day health coaching course for 18 pharmacists to improve patient focus in consultations. Using learning from the course and knowledge of dispensary processes, a flow chart was created to support management of the three categories of patient. Pharmacy staff trained to tailor their consultation to patient need using a coaching approach, including use of principles of the 4Es (Explore, Educate, Empower, Enable), a pharmacy-based model for short consultation.

Results Preliminary findings from the new approach included improved staff satisfaction, improved skill mix and positive feedback from patients. The main perceived disadvantage of using the above consultation style was the fear of increasing the time for consultations, however, this appears unfounded. A need for a dedicated counselling area to improve privacy in consultations was identified.

Conclusions Provision of a patient-centred consultation framework in a dispensary environment, using a coaching approach, has improved focus on patient needs, continuing the journey towards patientcentred care.

\section{INTRODUCTION}

The hospital pharmacy dispensary is a very busy work environment and the high turnover of work can feel stressful for pharmacy team members. Our patients may also feel under pressure, often having waited significant amounts of time to see the other health professionals prior to attending the pharmacy. In addition, they may have received news about their conditions which they are still processing. This means that both pharmacy team members and patients may not be best placed to undertake conversations about medicines adherence, safety or use at this time. Indeed, there have been concerning reports about violence towards pharmacists from disgruntled patients. ${ }^{1}$ There are parallels in community pharmacy: patients may come directly to the pharmacy from visiting their general practitioner (GP) practice where they have received condition-related information or may fit in a visit the pharmacy as part of their already full day.

Against this background many of us have been taught, in both undergraduate and postgraduate studies, that the fundamental role of pharmacy support for patients is 'telling your patients how to take medicines'. In the UK, we refer to conversations with patients as 'patient counselling'. We contend that even the phrase is at best confusing (because we mean patient education) or at worst, misleading (as counselling has a therapeutic meaning itself). We create a mental list of what we think patients should be told and do our best to pass on this information. However, how many of our assumptions about what we tell patients are based on evidence? Information from community pharmacies in the UK in $2004^{2}$ suggests that as well as shorter waiting times, patients want access to information from their pharmacy. In a Canadian study in $2013^{3}$ of what patient want from hospital pharmacy services, patients wanted medication reviews, information about side effects and interactions and the paper suggests that meeting their needs supported a more positive experience. The Royal Pharmaceutical Society (in Great Britain) is coproducing guidance ${ }^{4}$ with patients to support community pharmacists meeting patient expectations.

Our current practice dominates any consideration we might have of the patient's receptiveness to what we have to say, what the patient thinks or feels about the consultation or whether they even want to speak to us at all. We are constantly being told to make our consultations more patients centred, so how much so is this really the case? Are our consultations actually patient centred?

\section{MEDICINES ADHERENCE: THE CHALLENGE}

In order to answer this, we need to address another question: what is the purpose of a consultation about medicines? We suggest that the value of a consultation lies in helping patients get the best health outcome from their medicines and this requires more than education. We are told that up to half of patients do not to take their medication as intended. ${ }^{5}$ In reality, this means that every other patient we see will not be taking his/her medicine as we expect or have advised which can result in suboptimal outcomes for his/her health. As use of medicine increases as a therapeutic intervention, so does the imperative to consider how we use consultation time with patients more effectively to help them get more from their medicines, a process known in the UK as medicines optimisation. ${ }^{6}{ }^{7}$ In the UK, recent government policy embraced the approach to move from compliance, where we tell 
patients what to do about medicines, to concordance, which requires agreement and this is embodied by the phrase 'no decision about me without me'. ${ }^{8}$ There is an urgent need to act: economic modelling estimates that suboptimal compliance contributes to enormous waste. For example, for patients with type 2 diabetes, it is estimated to cost the National Health Service (NHS) over $£ 100$ million per year in avoidable treatment costs in England. ${ }^{9}$ In a report published in $2015,{ }^{10}$ commissioned by NHS England, these costs are still considered relevant and increases between 2010 and 2014 are estimated at 11\%.

We need to work with patients to create engagement in improving health, increasing patient awareness of their role in managing their health, supporting patients to become active participants in their care and take responsibility for their health. When patients take more active responsibility for medicines choice, we will reduce issuing medicines to patients who do not want to take them and can improve adherence through concordant consultations.

In order to do this, we argue that pharmacy teams need to think differently about the way in which consultations are undertaken in order to improve effectiveness of medicines.

\section{TRAINING OPPORTUNITY}

With this in mind, London North West Healthcare NHS Trust pharmacy dispensary staff, based at Northwick Park Hospital in North West London, UK decided to take the opportunity to improve their consultation skills through the use of health coaching.

Health coaching has been defined as: 'A behavioural intervention that facilitates participants in establishing and attaining health-promoting goals in order to change lifestyle-related behaviours, with the intent of reducing health risks, improving self-management of chronic conditions, and increasing health-related quality of life'. ${ }^{11}$ Developed from the Goal, Reality, Option, Will (GROW) model used in business coaching, health coaching is being introduced into NHS practice for a wide variety of clinicians to support patient self-care and selfmanagement. ${ }^{12-15}$

In April 2014, London North West Hospitals NHS Trust pharmacy department commissioned the largest provider of Health Coaching in England, The Performance Coach, to deliver a 2-day training course to a cohort of 18 pharmacists from the two hospital sites. The course was delivered by Dr Andrew McDowell, a health psychologist and leader for design and delivery of health coaching courses for the NHS, and Professor Nina Barnett, a consultant pharmacist for older people, an experienced health coach and trainer, who has designed health coaching interventions for pharmacy practice. ${ }^{16}$ Recognising that we could not train all pharmacy staff in the health coaching, we sought to introduce aspects of this discipline into the everyday consultation for all pharmacy staff in a dispensary setting. To this end, all dispensary staff attended a $2 \mathrm{~h}$ introductory session which focused on small changes in practice. This included considering what staff would want if they were patients, considering the current consultation from the patient perspective and including moving from telling to asking approach. ${ }^{17}$ This was reinforced at weekly dispensary meetings with staff sharing successes and challenges of interventions. In order to support further skill development, the full course has been recommissioned for 2016 .

\section{ENSURING SAFE PRACTICE}

Delivering medicines to patients through safe process is critical to dispensary practice and good governance is required around all changes to established practice. Therefore, prior to any changes, an audit of the technical steps of the existing process for giving medicines to patients was undertaken to confirm adherence to minimum safety standards. The audit demonstrated that safe practice was in place and the team, therefore, felt secure in the decision to review consultation style, integrating health coaching into consultations. A flow chart was created detailing the steps required to support the journey towards more patient-centred consultations (see online supplementary appendix 1). This included the principles of the 4Es (Explore, Educate, Empower, Enable; see online supplementary appendix 2), a pharmacy-based model for short consultation ${ }^{16}$ which uses health coaching principles to support patient-centred conversations.

\section{DISPENSARY HEALTH COACHING PROCESS}

In order to provide consultations appropriate to our patients, three categories patients are considered:

1. Patients who do not wish to have a conversation about their medicines. This may be because they already have enough information or because they are in a hurry to leave. Our experience is that attempting to give patients information in this situation causes frustration for both patient and pharmacy team member.

2. Patients who are receptive to information about safe use of medicines and have no immediate concerns or questions about their medicines.

3. Patients who are receptive to information about safe use of medicines and have questions or concerns about their medicines.

Using these three categories, trained pharmacy staff tailor their consultation to patient need. The process is described in the flow chart (see online supplementary appendix 1 ).

Patients in the first group receive a very short consultation, focused entirely on safety. A typical conversation includes checking who the medicines is for, confirming allergies and highlighting the contact number for the organisations' medicines information patient helpline and information in the medication patient information leaflets provided by law with all dispensed medicines.

Patients in the second group are offered the opportunity to ask questions and if they have no questions are provided with appropriate information within our safety checklist.

Patients in the third group are offered an opportunity to ask questions and if they have questions, the consultation proceeds using a coaching approach, supported by the 4Es model.

\section{OUR FINDINGS}

In the first few weeks of the pilot, advantages observed so far from both staff and informal patient feedback include:

- Improved staff satisfaction. Staff has said that they prefer to be able to tailor consultations for patients, focusing on what they actually want/need to know.

- Reduced patient and pharmacy team member frustration having 'permission' to focus on patient safety where time was short.

- Improvement in using and optimising skill mix where pharmacy technicians and pharmacists were empowered to have the same type of conversations.

- Patients have told us they were happy with our consultations directly.

The main perceived disadvantage of using the above consultation style was the fear of increasing the time for consultations, however, this appears unfounded from our experience. We have 
identified a need for a dedicated counselling area to improve privacy in consultations.

Now that we have demonstrated the practicality of implementing this intervention, we intend to review our work with patient involvement and assess the intervention formally through patient and staff feedback questionnaires. Planned modernisation of the pharmacy dispensary will include provision of a consultation area.

\section{HOW COULD THIS APPLY MORE WIDELY?}

It is now accepted that patients should be at the centre of their healthcare. Recognising that there is patchy patient-centred practice in pharmacy, we hope this work will contribute to our vision that all pharmacy consultations will be patient centred. We are using coaching approach to consultations in a variety of ways and we encourage everyone to consider how their processes can be improved to ensure the patient is at the centre of the consultation and to make changes, large and small, in the direction of patientcentredness. Provision of a patient-centred consultation framework in our dispensary, using a coaching approach, has improved our focus on patient needs. This balances our previous focus on health professional needs from consultations and will continue the journey towards patient-centred care.

Key messages

What is already known on this subject?

- Up to $50 \%$ of medicines are not taken as intended with poor adherence to medicines contributing to poor health outcomes and medicines waste.

- Hospital pharmacy consultations about medicines are often clinician centred and focus on information giving.

- There is a national drive in the UK to improve patient-centredness of care and this study explores patient-centred consultations in a hospital dispensary context.

\section{What this study adds?}

- It is possible to train clinical staff to use a more patient-centred approach in dispensary consultations.

- Triaging patients focuses the pharmacy team on patient needs from a consultation.

Contributors KF supported the dispensary staff in using the approach. NLB and KF created the flow chart, with help from other staff. NLB and KF wrote the article together and NLB edited the article.
Competing interests None declared.

Provenance and peer review Not commissioned; internally peer reviewed.

\section{REFERENCES}

1 Wiffen P. Working on the front line: how do you cope? Eur J Hosp Pharm 2014:21:319.

2 News feature. What do patients want from pharmacy? Pharm J 2004;273:510.

3 Gould O, Buckley P Doucette D. What patients want: preferences regarding hospital pharmacy services. Can J Hosp Pharm 2013;66:177-83.

4 Royal Pharmaceutical Society. Consultant Medicines charter for patients. What should you expect from your community pharmacist? https://www.rpharms.com/ news-story-downloads/consultation---medicines-charter-for-patients.pdf (accessed 25 Feb 2016).

5 NHS England. Medicines optimisation dashboard. https://www.england.nhs.uk/ ourwork/pe/mo-dash/ updated February 16 (accessed 25 Feb 2016).

6 Royal Pharmaceutical Society. Medicines optimisation: helping patients to make the most of medicines good practice guidance for healthcare professionals in England. May 2013. https://www.rpharms.com/promoting-pharmacy-pdfs/helping-patientsmake-the-most-of-their-medicines.pdf (accessed 25 Feb 2016).

7 National Institute for Health Care and Excellence (NICE). NICE guidelines [NG5] Medicines optimisation: the safe and effective use of medicines to enable the best possible outcomes. March 2015. https://www.nice.org.uk/guidance/ng5 (accessed 25 Feb 2016)

8 Equity and Excellence: Liberating the NHS. Department of Health. July 2010. https:// www.gov.uk/government/uploads/system/uploads/attachment_data/file/213823/dh_ 117794.pdf (accessed 25 Feb 2016).

9 York Health Economics Consortium, UCL School of Pharmacy, University of London Evaluation of the Scale, Causes and Costs of Waste Medicines. November 2010. http://discovery.ucl.ac.uk/1350234/1/Evaluation_of_NHS_Medicines_Waste_web_ publication_version.pdf (accessed 25 Feb 2016).

10 Bertie Hazell and Ross Robson (NHS BSA). Pharmaceutical waste reduction in the NHS. Version 1, June 2015. https://www.england.nhs.uk/wp-content/uploads/2015/ 06/pharmaceutical-waste-reduction.pdf (accessed 25 Feb 2016).

11 van Ryn $M$, Heaney CA. Developing effective helping relationships in health education practice. Health Educ Behav 1997;24:683-702.

12 Carter A, Tamkin P, Wilson S, et al. The Case for Health Coaching Lessons learned from implementing a training and development intervention for clinicians across the East of England. Institute for Employment Studies, 2015. https://eoeleadership.hee. nhs.uk/sites/default/files/The $\% 20$ Case $\% 20$ for $\% 20$ Health $\% 20$ Coaching $\% 20-\%$ 20Main\%20Report.pdf\#overlay-context=Evaluation (accessed 25 Feb 2016).

13 Newman P. The health coaching experience in NHS Midlands and East. NHS Institute for Innovation and Improvement, 2012. https://www.pcc-cic.org.uk/sites/ default/files/articles/attachments/dr_penny_newman_the_health_coaching experience_in_nhs_midlands_and_east_0.pdf (accessed 25 Feb 2016).

14 London Deanery. Training GP trainees in health coaching feasibility and impacts. https://www.networks.nhs.uk/nhs-networks/sha-shared-decision-making-andinformation-giving/documents/Impact $\% 20$ of $\% 20$ health $\% 20$ coaching $\% 20-\%$ 20London\%20Deanery.pdf (accessed 25 Feb 2016).

15 Ahluwalia $S$, de Silva D, Kumar $S$, et al. Teaching GP trainees to use health coaching in consultations with patients: evaluation of a pilot study. Educ Prim Care 2013;24:418-26.

16 Grimes L, Barnett N. Section 5. Health coaching in patient consultations. Consultation skills for pharmacy taking a patient centred approach. Centre for pharmacy postgraduate education. Feb 2014. http://www.consultationskills forpharmacy.com/docs/docb.pdf

17 Barnett N, Varia S, Jubraj B. Adherence: are you asking the right questions and taking the best approach? Pharm J 2013;291:153. 